\title{
Pressure-independent enhancement of cardiac hypertrophy in natriuretic peptide receptor A-deficient mice
}

\author{
Joshua W. Knowles, ${ }^{1}$ Giovanni Esposito, ${ }^{2}$ Lan Mao, ${ }^{2}$ John R. Hagaman, ${ }^{1}$ Jennifer E. Fox, ${ }^{1}$ \\ Oliver Smithies, ${ }^{1}$ Howard A. Rockman, ${ }^{2}$ and Nobuyo Maeda ${ }^{1}$
}

${ }^{1}$ Department of Pathology and Laboratory Medicine and Curriculum in Genetics and Molecular Biology,

University of North Carolina, Chapel Hill, North Carolina, USA

${ }^{2}$ Department of Medicine, Duke University Medical Center, Durham, North Carolina, USA

Address correspondence to: Nobuyo Maeda, Department of Pathology and Laboratory Medicine, CB\# 7525, University of North Carolina, Chapel Hill, North Carolina 27599-7525, USA.

Phone: (919) 966-6912; Fax: (919) 966-8800; E-mail: nobuyo@med.unc.edu.

Jennifer E. Fox's present address is: Tulane Medical School, New Orleans, Louisiana, USA.

Received for publication September 8, 2000, and accepted in revised form March 13, 2001.

\begin{abstract}
Mice lacking natriuretic peptide receptor A (NPRA) have marked cardiac hypertrophy and chamber dilatation disproportionate to their increased blood pressure (BP), suggesting, in support of previous in vitro data, that the NPRA system moderates the cardiac response to hypertrophic stimuli. Here, we have followed the changes in cardiac function in response to altered mechanical load on the heart of NPRA-null mice $\left(\mathrm{Npr}^{-/-}\right)$. Chronic treatment with either enalapril, furosemide, hydralazine, or losartan were all effective in reducing and maintaining BP at normal levels without affecting heart weight/body weight. In the reverse direction, we used transverse aortic constriction (TAC) to induce pressure overload. In the $\mathrm{Npr1}^{-/-}$mice, TAC resulted in a 15-fold increase in atrial natriuretic peptide (ANP) expression, a 55\% increase in left ventricular weight/body weight $(\mathrm{LV} / \mathrm{BW})$, dilatation of the $\mathrm{LV}$, and significant decline in cardiac function. In contrast, banded $\mathrm{Npr}^{+/+}$mice showed only a threefold increase in ANP expression, an 11\% increase in LV/BW, a $0.2 \mathrm{~mm}$ decrease in $\mathrm{LV}$ end diastolic dimension, and no change in fractional shortening. The activation of mitogen-activated protein kinases that occurs in response to TAC did not differ in the $\mathrm{Npr}^{+/+}$and $\mathrm{Npr}^{-/-}$mice. Taken together, these results suggest that the NPRA system has direct antihypertrophic actions in the heart, independent of its role in BP control.
\end{abstract}

J. Clin. Invest. 107:975-984 (2001).

\section{Introduction}

The natriuretic peptide system plays a crucial role in blood pressure (BP) and blood volume (BV) homeostasis. Increases in atrial stretch trigger the release of atrial natriuretic peptide (ANP) and brain natriuretic peptide (BNP), which act through natriuretic peptide receptor A (NPRA) in the kidneys and vasculature to increase natriuresis, diuresis, and vasorelaxation (1-4).

Elevations in circulating ANP and BNP are cardinal features of cardiac hypertrophy and heart failure in both humans and animal models (5-8), and induction of the ANP gene is one of the most robust responses to hypertrophic stimuli in the heart (9-12). Recent results suggest that these natriuretic peptides are not simply involved in $\mathrm{BP}$ and $\mathrm{BV}$ homeostasis but that they are also directly involved in moderating the cardiac growth response to hypertrophic stimuli. For example, the NPRA system has intrinsic growth inhibitory properties in noncardiac and cardiac cells in vitro (13). In endothelial and vascular smooth muscle cells (VSMCs), ANP is antimitogenic (14-17) and in cultured neonatal rat cardiomyocytes, ANP both attenuates the growth response to adrenergic stimuli (18) through a pathway that requires extracellular signal-related pro- tein kinase (ERK) activation (19) and induces apoptosis (20). Furthermore, NPRA knockout mice (which have greatly attenuated responses to ANP and BNP) not only have increased BP, but also display marked cardiac hypertrophy and chamber dilatation by 3 months of age (21), whereas other mutant mice with similar increases in BP do not have this hypertrophic phenotype (22). These observations have led to the hypothesis that the NPRA signaling pathway plays an important autocrine role in the prevention of cardiac hypertrophy and heart failure beyond its effects on $\mathrm{BP}$ and $\mathrm{BV}$ regulation.

To test the hypothesis that the NPRA pathway directly modulates the hypertrophic response we compare the response of $\mathrm{Npr}^{+/+}$and $\mathrm{Npr}^{-/-}$mice to a pressure overload induced by transverse aortic constriction (TAC). We have also investigated the natural progression to cardiac hypertrophy that occurs in $\mathrm{Npr1}^{-/}$mice in the absence of TAC and the effects of chronic (3 months) BP normalization by enalapril, furosemide, hydralazine, or losartan. We conclude that the NPRA system indeed plays a primary role in moderating cardiac hypertrophy in vivo independently of its effects on $\mathrm{BP}$ regulation. 


\section{Methods}

Mouse experiments were carried out under protocols approved by the Institutional Animal Care and Use Committees of the University of North Carolina and Duke University.

Experimental mice. Unless otherwise stated, the $\mathrm{Npr}^{-/}$ and $N p r 1^{+/+}$mice used in this study were F4 or F5 generation of a mixed 129/C57BL6 genetic background derived from the original mutants reported previously (21). The extreme cardiac hypertrophy and sudden death observed in the F2 generation of male mice were no longer present in this particular stock of mutants, presumably because of genetic drifts and loss of modifying loci. Blood pressures and heart weight/body weight $(\mathrm{HW} / \mathrm{BW})$ in male and female mice in this group were not significantly different. Thus, both males and females were used in this experiment. Animals were genotyped by multiplex PCR using: Primer A (5'-GCTCTCTTGTCGCCGAATCT-3') corresponding to a sequence $5^{\prime}$ to the mouse $N$ pral gene common to both alleles; Primer B (5'-TTTAGAGCAGGTGAGAGCGA-3') corresponding to an exon 1 sequence only present in the intact mouse allele; and Primer C (5'-GCTTCCTCGTGCTTTACGGT-3') a sequence in the neomycin resistance cassette only present in the null allele. The PCR reaction from tail DNA included $50 \mathrm{mM}$ Tris, $20 \mathrm{mM}$ ammonium sulfate, $1.5 \mathrm{mM} \mathrm{MgCl} 2,10 \%$ DMSO, 100 $\mu \mathrm{M}$ dNTP, $2 \mathrm{U}$ of Taq polymerase, and $40 \mathrm{nM}$ primers. The PCR cycling conditions were $94^{\circ} \mathrm{C}$ for 30 seconds, $60^{\circ} \mathrm{C}$ for 30 seconds, and $72^{\circ} \mathrm{C}$ for 1 minute for 35 cycles. PCR products were resolved on a $2 \%$ agarose gel. The endogenous band is $330 \mathrm{bp}$, and the targeted band is $250 \mathrm{bp}$. All mice were fed a normal chow diet.

Telemetric blood pressure analysis. Mice were anesthetized with $2 \%$ isoflurane. A 2 - to $3-\mathrm{cm}$ midline incision was made in the dorsal abdomen to allow exposure of the abdominal aorta from the renal artery to the iliac bifurcation. Eight- to ten-month-old mice were used for this experiment because the procedure is only possible with mice larger than $30 \mathrm{~g}$. The aorta was delicately teased away from surrounding tissue and from the vena cava. A ligature was placed around the aorta just caudal to the left renal vein, and the aorta was irrigated with $2 \%$ lidocaine. The ligature was retracted, and the tip of a PA-C20 pressure transducing catheter (Data Sciences, St. Paul, Minnesota, USA) was introduced into the aorta 1-2 $\mathrm{mm}$ cranial to the iliac bifurcation using the tip of a 25-gauge needle. The catheter tip was secured with Vetbond (3M, St. Paul, Minnesota, USA). The transducer unit was placed into the abdomen, and the incision was closed with 4.0 suture. The BP signal from the transducer was monitored using a receiver unit placed under the cage. Data were collected, stored, and analyzed using Dataquest A.R.T. software (Data Sciences). Base-line BPs were not taken until at least 10 days after surgery to allow mice to regain normal diurnal rhythms. Various doses of enalapril, furosemide, hydralazine, propranolol (all from Sigma-Aldrich, St. Louis, Missouri, USA) or losartan (a generous gift of R.
Smith, Merck and Co., Whitehouse Station, New Jersey, USA) were added to the drinking water of the animals, and BP measurements were taken continuously for at least 1 week. A washout period of at least 1 week, with monitoring of BP to ensure recovery to base-line values, was allowed between administration of different drugs.

Tail-cuff BP analysis. BP and heart rate (HR) was measured noninvasively on conscious, restrained mice as described elsewhere (23) (Visitech, Apex, North Carolina, USA), when the animals were 3-4 months of age. All BPs were calculated as the average of at least five measurements per day for 6 consecutive days.

Chronic antibypertensive drug treatment. In the chronic administration studies, the drugs were used at the following doses; enalapril $(0.10 \mathrm{~g} / \mathrm{l})$, furosemide $(0.10 \mathrm{~g} / \mathrm{l})$, hydralazine $(0.05 \mathrm{~g} / \mathrm{l})$, propranolol $(0.08 \mathrm{~g} / \mathrm{l})$, or losar$\tan (0.12 \mathrm{~g} / \mathrm{l})$. Treatment started at weaning (3 weeks of age) and continued until sacrifice at 4 months of age. The drugs were added directly to the drinking water, which was changed at least weekly. In adult $\mathrm{Npr1^{-/ }}$ mice, both left ventricular (LV) and right ventricular (RV) size is equally increased compared with that of Npr $1^{+/+}$mice (21). However, as the difference in RV weight is small compared with the overall difference in HW, we took the HW/BW as the indicator for cardiac hypertrophy. Three-week-old pups were sacrificed after anesthetic overdose to determine the HW/BW at this age in both genotypes.

Transverse aortic constriction. Mice (3-6 months) were anesthetized with a mixture of ketamine $(100 \mathrm{mg} / \mathrm{kg})$ and xylazine $(2.5 \mathrm{mg} / \mathrm{kg})$ and TAC was performed as described previously (24). Sham-operated mice underwent the same operation except for aortic constriction.

Echocardiographic analysis. Transthoracic two-dimensional guided M-mode echocardiography was performed in both anesthetized $(n=8)$ and nonanesthetized mice $(n=52)$ before and 7 days after induction of pressure overload to ensure a maximal hypertrophic response. Measurements were done using an HDI 5000 echocardiograph (ATL, Bothell, Washington, USA) as described previously (25).

$R N A$ analysis. At 7 days after surgery, mice were sacrificed after anesthetic overdose. The heart was removed, and the individual chambers were dissected free. LVs were snap frozen in liquid nitrogen. RNA was purified from snap-frozen left ventricles with TRIzol reagent (Life Technologies, Grand Island, New York, USA) following the manufacturer's directions. We used standard Northern blot techniques on samples containing $20 \mu \mathrm{g}$ of RNA. A 650-bp fragment of a cDNA-encoding rat ANP (subcloned into pGem) (24) and a 315-bp fragment of the mouse GAPDH gene (Ambion Inc., Austin, Texas, USA) (subcloned into pBluescript II KS+; Stratagene, La Jolla, California, USA) served as templates for the generation of probes radiolabeled with ${ }^{32} \mathrm{P} \mathrm{dCTP}$ (Dupont NEN, Boston, Massachusetts, USA) with a Random Primed DNA Labeling Kit (Boehringer Mannheim, Indianapolis, Indiana, USA), following the manufacturer's directions. Blots were hybridized using 
QuickHyb solution (Stratagene) and washed in 3XSSC, $0.1 \%$ SDS. ANP message levels were quantified using a Phosphorimager (Fugifilm, Stamford, Connecticut, USA) and normalized to GAPDH expression.

MAP kinase assays. Seven days after surgery, mice were sacrificed following anesthetic overdose. The heart was removed, the individual chambers were dissected free, and the LVs were snap frozen in liquid nitrogen. LVs were homogenized in $2 \mathrm{ml}$ of RIPA buffer (50 mM tris$\mathrm{HCl}[\mathrm{pH}$ 7.5], $150 \mathrm{mM} \mathrm{NaCl}, 1 \% \mathrm{NP}-40,0.25 \%$ deoxycholate) and centrifuged at $40,000 \mathrm{~g}$ for 20 minutes. Two milligrams of clarified myocardial extract in $2 \mathrm{ml}$ of RIPA was immunoprecipitated at $4{ }^{\circ} \mathrm{C}$ for 2 hours using antibodies to ERK2-p42/ERK1-p44, p38 $\alpha$, p38 3 , and JNK1-p46/JNK3 (Santa Cruz Biotechnology Inc., Santa Cruz, California, USA) and protein A-Agarose or protein-G-Agarose (Boehringer Mannheim). The immunoprecipitates were collected by centrifugation at $18,000 \mathrm{~g}$ for 10 minutes at $4^{\circ} \mathrm{C}$, and the pellet was washed once with RIPA buffer and twice with the appropriate protein kinase buffer (20 mM HEPES [pH 7.0], 10 $\mathrm{mM} \mathrm{MgCl}_{2}, 1 \mathrm{mM}$ DTT sedimented [ERK2-p42/ERK1$\mathrm{p} 44, \mathrm{p} 38, \mathrm{p} 38 \beta$ kinase assay buffer], $20 \mathrm{mM}$ HEPES [pH 7.0], and $10 \mathrm{mM} \mathrm{MgAcetate}$ [JNK1-p46/JNK3 kinase assay buffer]). Samples were resuspended in $40 \mu \mathrm{l}$ of kinase buffer with $20 \mu \mathrm{M}$ ATP, $\left[\gamma^{32} \mathrm{P}\right]$ ATP $(20 \mu \mathrm{Ci} / \mathrm{ml})$ and myelin basic protein (MBP) $(0.25 \mathrm{mg} / \mathrm{ml})$ or GSTcJun $(10 \mu \mathrm{g})$ and incubated at $32^{\circ} \mathrm{C}$ for 20 minutes. Reactions were terminated with $40 \mu \mathrm{l}$ of $2 \mathrm{X}$ Laemmli loading buffer, and $30 \mu \mathrm{l}$ of each reaction was electrophoresed through a $15 \%$ polyacrylamide:tris-glycine gel. Phosphorylated MBP and GST-cJun on dried gels were quantified with a Phosphorimager (Amersham Pharmacia, Piscataway, New Jersey, USA) (26).

Statistical analysis. Data were analyzed using either the JMP (SAS Institute, Cary, North Carolina, USA) or SYSTAT (SYSTAT Inc., Evanston, Illinois, USA) software packages. All data are reported as mean \pm SE.

\section{Results}

NPRA-null mice have larger than normal hearts throughout life. The natural course of cardiac hypertrophy of $\mathrm{Npr1}^{-1-}$ mice is illustrated in Figure 1, which shows the $\mathrm{HW}$ of mice in a C57BL/ 6 genetic background. Even at 1 day of age, the hearts of $\mathrm{NprI}^{-/-}$mice are significantly larger with the HW/BW $140 \%$ that of $\mathrm{Npr1}^{+/+}$mice $\left(7.2 \pm 0.3 \mathrm{mg} / \mathrm{g}[n=3]\right.$ in $\mathrm{Npr}^{-/-}$mice versus $5.1 \pm 0.1$ $\mathrm{mg} / \mathrm{g}[n=10]$ in $\mathrm{Npr}^{+/+}$mice; $\left.P<0.0001\right)$. During the first 3 weeks, the HW increases approximately tenfold and the HW/BW of $\mathrm{Nrr}^{-/-}$mice at day 21 is $150 \%$ that of $\mathrm{Ppr}^{+/+}$mice $\left(10.7 \pm 0.7 \mathrm{mg} / \mathrm{g}[n=4]\right.$ in $\mathrm{Npr1}^{-/-}$mice versus $7.1 \pm 0.2 \mathrm{mg} / \mathrm{g}[n=18]$ in $\mathrm{Npr1}^{+/+}$mice; $P<$ 0.0001). From weaning until 4 months of age, the HW doubles and the HW/BW of $\mathrm{Npr1}^{-/-}$mice is $130 \%$ that of $\mathrm{Npr}^{+/+}$mice $\left(6.9 \pm 0.2 \mathrm{mg} / \mathrm{g}[n=15]\right.$ in $\mathrm{Npr1}^{-/-}$mice versus $5.3 \pm 0.1 \mathrm{mg} / \mathrm{g}[n=26]$ in $N p r 1^{+++}$mice; $P<$ $0.0001)$. Thus, the lack of NPRA results in an enlargement of the heart that is present at birth and persists throughout life.
The HW/BW of our population of experimental mice on a mixed genetic background was very similar to mice on a C57BL/ 6 genetic background. However, these animals, as well as mice on a C57BL/ 6 genetic background, differ from F2 generations reported previously (21). At 4 months of age the BPs of male $\mathrm{Npr1}^{-1-}$ mice are $136 \pm 2 \mathrm{mmHg}(n=21)$ and not significantly different from those in females $(141 \pm 2 \mathrm{mmHg} ; n=16)$. Similarly, HW/BW in males and females is not different $(6.6 \pm 0.2 \mathrm{mg} / \mathrm{g}[n=20]$ and $6.7 \pm 0.2 \mathrm{mg} / \mathrm{g}[n=16]$, respectively). The loss of male/female differences in this population are currently unknown but may be due to the segregation of some modifying loci. The exaggerated male cardiac phenotype is not present in other $\mathrm{Npr}^{-/-}$mice independently made by Lopez et al. (27).

There is no difference in hematocrit $(47 \pm 2 \%[n=8]$ in $\mathrm{Npr1}^{+/+}$versus $44 \pm 2 \%[n=9]$ in $\mathrm{Npr1}^{-/-}$) or BW (male: 36 $\pm 3 \mathrm{~g}[n=5]$ in $\mathrm{Npr}^{+/+}$versus $34 \pm 1 \mathrm{~g}[n=22]$ in $\mathrm{Npr}^{-/-}$; female: $23 \pm 2 \mathrm{~g}[n=9]$ in $\mathrm{Npr}^{+/+}$versus $25 \pm 1 \mathrm{~g}[n=16]$ in $\mathrm{Npr1}^{-/-}$) between the genotypes under basal conditions. In addition, there are no differences between $\mathrm{NprI}^{+/+}$and $\mathrm{Npr1}^{-/-}$mice with respect to water intake, urine volume, or sodium excretion (data not shown) which agrees with a previous report by Dubois et al. (28).

Telemetric $B P$ recording and determination of effective doses of antibypertensive drugs. Adult $\mathrm{Npr}^{-1-}$ mice have elevated BP as determined by tail-cuff analysis. In other genetically altered mice in which the tail-cuff $\mathrm{BP}$ is similarly elevated, such as endothelial nitric oxide synthase-deficient mice, the HW/BW is not greater than that of wild-type (22). However, because tail-cuff analyses are performed during the light cycle while mice are not normally active, we considered the possibility that the difference in $\mathrm{HW} / \mathrm{BW}$ in $\mathrm{Npr}^{-1-}$ mice might be accounted for by undetected increases in BP in these mice during periods of darkness when the mice are

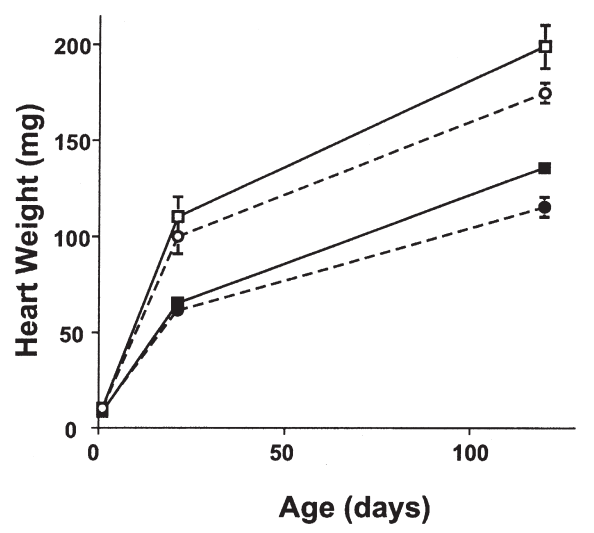

\section{Figure 1}

Natural history of cardiac hypertrophy in $\mathrm{Npr}^{-1-}$ mice. The differences between the genotypes are significant at all three time points, days 1,21 , and $120(P<0.001)$. Npr1 $1^{-/-}$males and females are represented by open squares and circles, respectively. $\mathrm{Npr}^{+/+}$males and females are represented by filled squares and circles, respectively. Sex was not determined at the day 1 time point. 


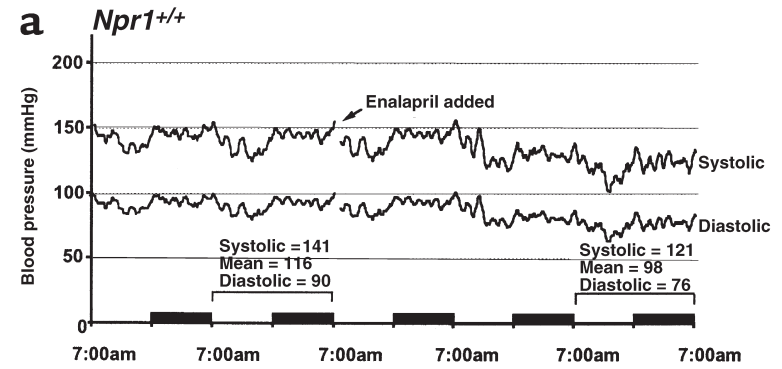

b $\mathrm{Npr} \%$

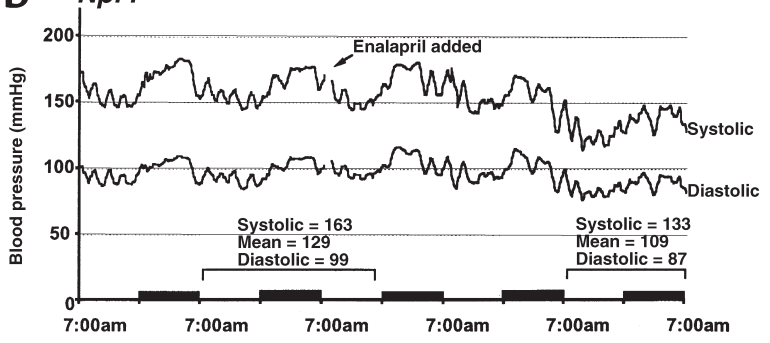

Figure 2

Representative 5-day tracings of systolic and diastolic BP continuously recorded using a telemetric system. (a) An $\mathrm{Npr}^{1+/+}$ mouse and (b) an $\mathrm{Npr}^{-1-}$ mouse. Both mice have diurnal rhythms with about a $10 \mathrm{mmHg}$ increase in BP during periods of darkness. Arrows indicate the addition of enalapril $(0.12 \mathrm{~g} / \mathrm{l})$ to the drinking water. Enalapril decreases the BP in both $\mathrm{Nprr}^{+/+}$and $\mathrm{Npr1}^{-/-}$mice.

active. To address this issue, we used a telemetric BP recording system to monitor the $\mathrm{BP}$ of $\mathrm{Npr1}^{-/-}$mice continuously. Concurring with the tail-cuff assays, the $\mathrm{BP}$ of $\mathrm{Npr1}^{-/-}$mice is much higher than that of $\mathrm{Npr1}^{+/+}$ mice: the average systolic/diastolic BP of $\mathrm{Npr1}^{-/-}$mice during 12 hours of the light cycle is 164/94 $(n=4)$, whereas the average for $\mathrm{Nprl}^{+/+}$mice is $130 / 79(n=2)$. The telemetry showed that $\mathrm{BP}$ increases during periods of darkness/activity: the average systolic/diastolic BP of $\mathrm{Npr}^{-/-}$mice during the 12 hours of the dark cycle is $178 / 108(n=4)$, whereas the average for $\mathrm{Npr}^{+/+}$mice is $139 / 89(n=2)$ (Figure 2). Throughout the 12 weeks of monitoring, we did not detect any peculiar alterations in the BP of $\mathrm{Npr1}^{-/-}$mice. Thus, the NPRA-null mice do not have disproportionately elevated $\mathrm{BP}$ when they are active. Also, although it is clear that the tail-cuff method of BP analysis on conscious mice is extremely reproducible, robust, efficient and relatively inexpensive, it is also clear that this method significantly underestimates systolic BP (compare $\mathrm{Npr1}^{-/-} \mathrm{BP}$ in Figures $2 \mathrm{~b}$ and $3 \mathrm{a}$ ).

We then used the telemetric BP recording system to perform a series of pilot experiments to determine the optimal doses of several drugs for chronic antihypertensive treatment of $\mathrm{Npr1}^{-/-}$mice. An example of telemetric BP tracing is seen in Figure 2. The drugs were given in the drinking water for approximately 1 week, and in most cases two doses of each drug were tested. In $\mathrm{Npr}^{-/-}$mice, an ACE inhibitor, enalapril $(0.12 \mathrm{~g} / \mathrm{l})$, decreased the systolic BP by $15 \mathrm{mmHg}$ and the dias- tolic by $10 \mathrm{mmHg}$. Doubling the dose of enalapril did not result in a greater decrease in BP. The diuretic, furosemide $(0.1 \mathrm{~g} / \mathrm{l})$ decreased the systolic and diastolic BP of $\mathrm{Npr}^{-/-}$mice by $20 \mathrm{mmHg}$ and $5 \mathrm{mmHg}$, respectively. The vasodilator, hydralazine $(0.05 \mathrm{~g} / \mathrm{l})$, and the angiotensin II receptor blocker, losartan $(0.06$ $\mathrm{g} / \mathrm{l})$, decreased the systolic and diastolic BP of $\mathrm{Npr}^{-/-}$ mice by $10 \mathrm{mmHg}$ and $5 \mathrm{mmHg}$, respectively, and there was no greater effect with either drug when the dose was doubled. The $\beta$-adrenergic blocker, propranolol $(0.08$ or $0.16 \mathrm{~g} / \mathrm{l})$ lowered the BP in $\mathrm{Npr1}^{-/-}$mice by approximately $3 \mathrm{mmHg}(\mathrm{NS})$, although the heart rate decreased in these mice by about $10 \%$, indicating proper administration. The lowest tested dose of each drug that reduced the BP of $\mathrm{Npr}^{-/-}$mice to or less than that of $\mathrm{Npr}^{+/+}$mice according to the telemetric analysis was used in the chronic antihypertensive treatment studies.

Chronic antibypertensive treatment does not reduce cardiac bypertrophy in $\mathrm{Npr}^{-/-}$mice. In both humans and animal models of hypertension, a primary cause of LV hypertrophy (LVH) is increased BP (29), and even modest reductions in this mechanical load normally lead to a decrease in LVH (30-37). To determine whether chronic BP reduction alters the course of the naturally occurring cardiac hypertrophy in $\mathrm{Npr1}^{-/-}$mice, we evaluated the effects of chronic administration of five commonly used antihypertensive agents given in the drinking water from the time of weaning at approximately 20 days of age until sacrifice at 4 months of age. At weaning, the hearts of the mice are not fully developed and weigh half of their adult weight (Figure 1), allowing sufficient room to observe the effects of BP normalization. Enalapril $(0.1 \mathrm{~g} / \mathrm{l})$, furosemide $(0.1 \mathrm{~g} / \mathrm{l})$, hydralazine $(0.05 \mathrm{~g} / \mathrm{l})$, and losartan $(0.06$ or $0.12 \mathrm{~g} / \mathrm{l})$ all decreased the tail-cuff $\mathrm{BP}$ of $\mathrm{Npr1}^{-/-}$mice to levels at or below those seen in untreated $\mathrm{Nprl}^{+/+}$mice (Figure 3a). Propranolol $(0.08 \mathrm{~g} / \mathrm{l})$ did not affect $\mathrm{BP}$ of $\mathrm{Npr}^{-/-}$mice. These drugs also had varied effects on the hemodynamics in these animals as indicated by changes in HR. Enalapril treatment resulted in a $6 \%$ increase in HR ( $687 \pm 6$ vs. $649 \pm 6$ beats per minute [bpm]), whereas furosemide treatment caused a $10 \%$ decrease in HR (582 $\pm 5 \mathrm{bpm})$. Hydralazine, losartan, and propranolol all caused modest, nonsignificant reductions in HR $(614 \pm 15,615 \pm 7$, and $622 \pm 14 \mathrm{bpm}$, respectively). However, despite the effective normalization of BP via the chronic administration of enalapril, furosemide, hydralazine, or losartan, HW/BW was not reduced (Figure $3 \mathrm{~b}$ ). There was a trend toward a reduction in $\mathrm{HW} / \mathrm{BW}$ in the furosemide-treated group $(P=0.08)$, and we cannot completely exclude the possibility that higher doses of furosemide may reduce blood volume and affect cardiac hypertrophy in these mice.

A comparison of the BP and HW/BW from individual $\mathrm{Npr}^{-/-}$mice $(n=113)$ likewise shows no significant relationship between $\mathrm{BP}$ and $\mathrm{HW} / \mathrm{BW}$ in the $N p r 1^{-/-}$mice (Figure 4) $\left(P=0.09\right.$, ANOVA; $\left.r^{2}=0.02\right)$. Together, these data indicate that cardiac hypertro- 

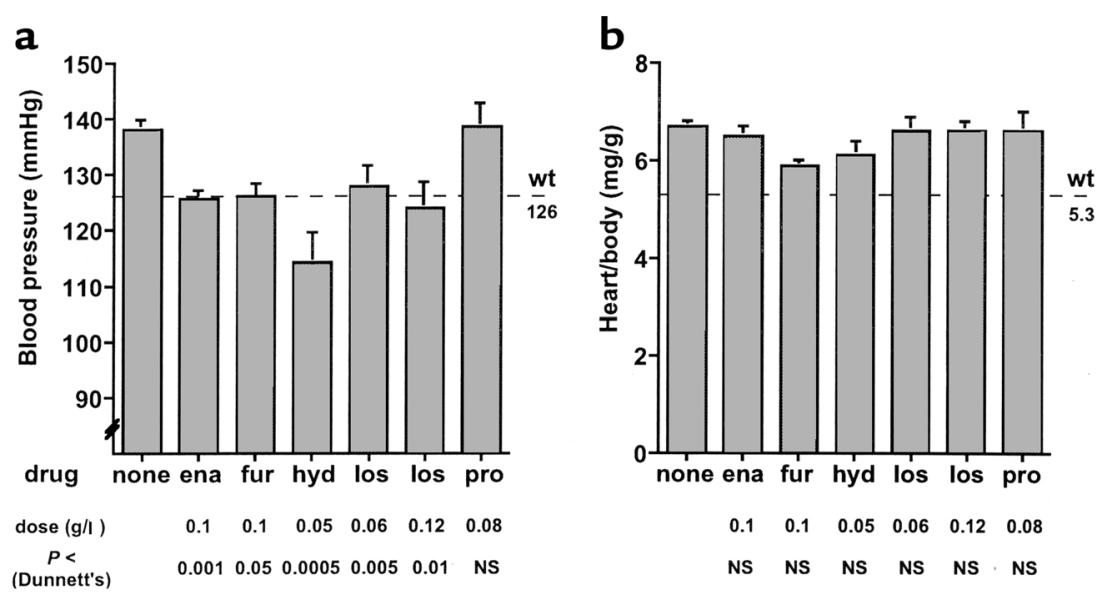

Figure 3

Chronic BP normalization and cardiac hypertrophy in $\mathrm{Npr}^{-1-}$ mice. (a) BPs of Npr1-/- mice chronically treated with no drug $(n=21$ male, 16 female), enalapril (ena) ( $n=13$ male, 7 female), furosemide (fur) ( $n=$ eight male, nine female), hydralazine (hyd) ( $n=$ four male, six female), losartan (los) (low dose, $n=$ seven male, seven female; high dose, $n=$ six male, three female), or propranolol (pro) ( $n=$ eight male) from 21 days of age until sacrifice at 4 months of age. No sex differences were present in any group. Drugs were given in the doses indicated below each bar. All drugs, except propranolol, lowered BP. P values (by Dunnett's test versus Npr1-/- control animals) are also given below each bar. For reference, the average value of BP for $\mathrm{Npr}^{1^{+/+}}$mice $(n=20)$ is shown by the dashed line. Error bars represent SE. (b) HW/BW of $\mathrm{Npr}^{1^{-/-}}$mice. Chronic antihypertensive treatment did not affect cardiac hypertrophy in $\mathrm{Npr}^{1-/-}$ mice. For reference, the average value of $\mathrm{HW} / \mathrm{BW}$ for $\mathrm{Npr}^{+/++}$mice $(n=10)$ is shown at the right.

phy in $\mathrm{Npr1}^{-/-}$mice occurs/persists even when the BPs of the mice are essentially normal.

NPRA-deficient mice have an enhanced cardiac bypertrophic response to pressure overload. Our previous work has shown that 7 days after surgical constriction of the transverse aorta is optimal to examine the effects of pressure overload on LVH (24). The pressure overload induced by TAC caused a much greater increase in the $\mathrm{LV} / \mathrm{BW}$ in $\mathrm{Npr}^{-/-}$mice than in $\mathrm{Npr}^{+/+}$mice (Figure 5a). Thus, the NPRA-deficient mice that received TAC for 1 week had a $55 \%$ increase in $\mathrm{LV} / \mathrm{BW}$ compared to sham-operated $\mathrm{Npr}^{-/-}$mice $(7.0 \pm 0.3 \mathrm{mg} / \mathrm{g}$ in TAC, $4.5 \pm 0.2 \mathrm{mg} / \mathrm{g}$ in sham mice), while in $\mathrm{Npr}^{+1^{++}}$mice TAC caused only an $11 \%$ increase in the LV/BW $(4.5 \pm$ $0.3 \mathrm{mg} / \mathrm{g}$ in TAC, $4.0 \pm 0.2 \mathrm{mg} / \mathrm{g}$ in sham mice $)(P<$ $0.00001 \mathrm{Npr1}^{-/-}$TAC versus $\mathrm{Npr1}^{+/+} \mathrm{TAC}$, TukeyKramer honestly significant difference [HSD]). (TAC produced equivalent systolic pressure gradients [SPGs] in the two groups of mice $\left[65 \pm 6 \mathrm{mmHg}\right.$ in $\mathrm{Nprl}^{+/+}$ mice, $n=18$, compared with $59 \pm 7 \mathrm{mmHg}$ in $\mathrm{Npr}^{-/-}$ mice, $n=16]$ ). No sex differences in the LV/BW in any of the groups were observed. ANP message levels, a reliable marker of cardiac hypertrophy, were 2.1-fold higher in banded $\mathrm{Npr}^{-/-}$mice compared with banded $\mathrm{Npr}^{+/+}$mice $\left(28,100 \pm 1,900 \mathrm{U}\right.$ in $\mathrm{Npr}^{-{ }^{-/}}$mice versus $13,300 \pm 4,300 \mathrm{U}$ in $\mathrm{Npr}^{+/+}$mice; $P<0.05$ TukeyKramer HSD) (Figure 5b). In this set of animals, the difference in $\mathrm{LV} / \mathrm{BW}$ in the $\mathrm{NprI}^{+/+}$and $\mathrm{Npr}^{-/-}$sham mice is not significant $(P=0.09)$. However, the size of each of the chambers of the heart (not just the LV) is affected by the lack of NPRA. Thus, the HW/BW of $\mathrm{Npr}^{+/+}$and $\mathrm{Npr}^{-/-}$sham mice are significantly different $(5.3 \pm 0.3 \mathrm{mg} / \mathrm{g}$ and $6.2 \pm 0.2 \mathrm{mg} / \mathrm{g}$, respectively) $(P<0.05)$, which agrees with the previous report $(21)$.
Because basal blood pressure is higher in $\mathrm{Npr1}^{-/-}$mice and the gradient induced by TAC was similar between $\mathrm{Npr1}^{-/-}$and $\mathrm{Nprl}^{+/+}$mice, the total load on the heart (LV systolic pressure) may be greater in $\mathrm{Npr1}^{-/-}$mice than in $\mathrm{Npr}^{+/+}$mice. This pressure difference potentially accounts for the disparity in LV/BW of $\mathrm{Npr}^{+/+}$and $\mathrm{Npr}^{-/-}$mice after TAC. To examine this possibility, we plotted LV/BW of individual animals that received TAC (expressed as a percent of mean values of sham) as a function of the LV systolic pressure (measured as the pressure in the right carotid artery proximal to the aortic constriction). The measurement of LV systolic pressure reflects the absolute load on the heart because it is a function of both the systemic BP and the pressure gra-

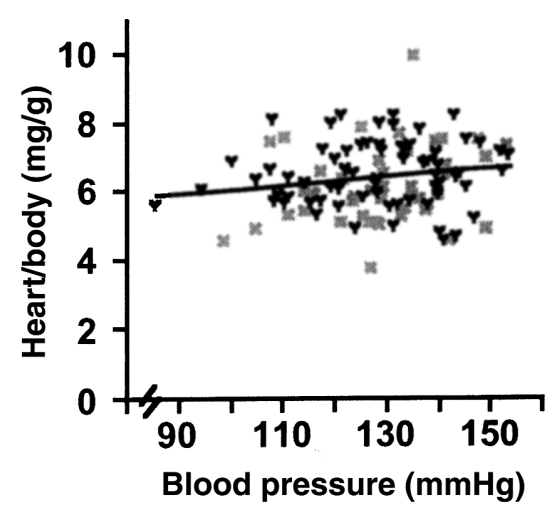

Figure 4

$\mathrm{HW} / \mathrm{BW}$ expressed as a function of BP in $\mathrm{Npr}^{-1-}$ male (black Y) and female (gray $\mathrm{X}$ ) mice. Values for all animals from all treatment groups (control, enalapril, furosemide, hydralazine, losartan, and propranolol) ( $n=66$ male, 47 female) that were used in the chronic BP reduction studies are shown. $P=0.09$ by ANOVA; $r^{2}=0.02$. 
a

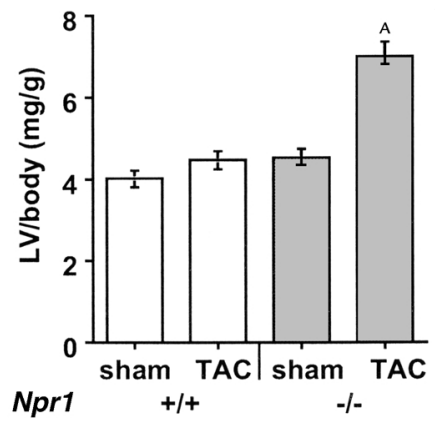

b

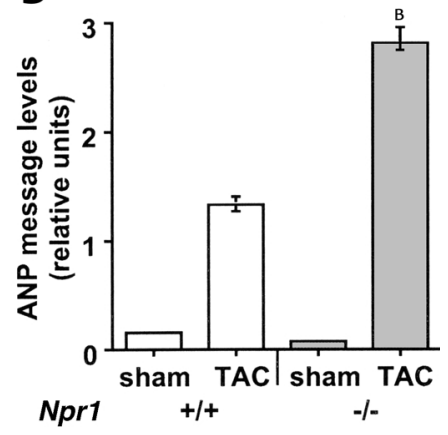

\section{Figure 5}

$\mathrm{Npr}^{-1-}$ mice have an enhanced cardiac hypertrophic response to TAC. (a) LV/BW in $\mathrm{Npr}^{+/+}$and $\mathrm{Npr1} 1^{-/-}$ mice. $\mathrm{Npr1^{+/+ }}$ sham ( $n=$ five male, five female); $\mathrm{Npr1^{+/+ }}$ TAC ( $n=$ eight male, nine female); Npr1-l- sham ( $n$ = five male, four female); Npr1 ${ }^{-/-} \operatorname{TAC}(n=3$ male, 21 female). ${ }^{A} P<0.00001$ versus $N p r 1^{+/+}$TAC by TukeyKramer HSD. (b) ANP message levels in LV as assessed by Northern analysis in $\mathrm{Npr}^{+/+}$and $\mathrm{Npr} 1^{-/-}$mice that were either sham operated or received TAC for 1 week. Values are normalized to GAPDH expression. A subset of hearts matched for SPG were chosen for this analysis (in this subset SPG is $53 \mathrm{mmHg}$ in $\mathrm{Npr1} 1^{+/+}$TAC animals and $45 \mathrm{mmHg}$ in Npr1-1- TAC animals). ${ }^{\mathrm{B} P}<0.05 \mathrm{ver}-$ sus Npr1+1+ TAC by Tukey-Kramer HSD. dient induced by TAC. As shown in Figure 6, the total cardiac load in $\mathrm{NprI}^{+/+}$and $\mathrm{Npr1}^{-/-}$mice are within the same range, but for any total pressure load, the $\mathrm{Npr1}^{-/-}$ mice have an enhanced hypertrophic response, suggesting that this enhancement is not simply a function of BP. Pressure overload causes $L V$ chamber dilation and worsening cardiac function in $\mathrm{Npr1^{-/ }}$ mice. In response to TAC, the LV chamber of the $\mathrm{Npr}^{-/-}$mice became significantly dilated, with the LV end diastolic dimension (LVEDD) increasing by an average of $0.4 \pm 0.2 \mathrm{~mm}(n=17)$ (Table 1). In contrast, the $N p r 1^{+/+}$mice showed small decreases in LVEDD in response to the pressure overload induced by TAC, with LVEDD decreasing by an average of $0.2 \pm$ $0.1 \mathrm{~mm}(n=19)$ (Figure 7a). Similarly, the LV end systolic dimension (LVESD) increased by $0.65 \pm 0.3 \mathrm{~mm}$ in $N p r 1^{-/-}$mice $(n=17)$, whereas LVESD decreased by 0.14 $\pm 0.2 \mathrm{~mm}$ in $N p r 1^{+/+}$mice $(n=19)$. The difference between the two genotypes was highly significant statistically $\left(P<4.0 \times 10^{-5}\right.$ for LVEDD and $P<2.0 \times 10^{-4}$ for LVESD by repeated measures ANOVA with post hoc Scheffe test).

The dilatation of the LV in the NPRA-deficient mice caused by pressure overload was accompanied by a worsening of cardiac function, as shown by a signifi- cant decrease in percent fractional shortening (\% FS) (Figure $7 \mathrm{~b})$, which averaged $6 \pm 4 \%(n=17)$. In contrast, the \% FS in $\mathrm{Npr1}^{+/+}$mice was unchanged by TAC $(n=19)$. Again, the difference between the two genotypes was highly significant $(P<0.004$ by repeated measures, ANOVA and post hoc Scheffe test). Sham operations had no effect on either LVEDD, LVESD, or $\% \mathrm{FS}$ in either $\mathrm{Npr}^{+/+}$or $\mathrm{Npr1} 1^{-/-}$mice. Taken together, the data show that NPRA-deficient mice have an enhanced hypertrophic response to pressure overload.

The enhanced bypertrophic response in TAC Npr1 $1^{-1-}$ mice is not accompanied by greater induction of mitogen-activated protein kinase activity. Four mitogen-activated protein kinase (MAPK) pathways, c-Jun-NH2-terminal kinase (JNK), the extracellular regulated kinase (ERK1/2), p38 $\alpha$, and p38 $\beta$, are known to be activated in response to cardiac overload induced by TAC. To determine whether the enhanced hypertrophic response seen in the $\mathrm{Npr1}^{-/-}$ mice is accompanied by changes in these pathways, we examined the level of activation of these four kinases 7 days after TAC when all four kinases have been shown to be activated (26). In the sham-operated mice, there was no difference in the level of activation of all four kinases between the $\mathrm{NprI}^{+/+}$and $\mathrm{Npr}^{-1^{-/}}$mice (Figure

Table 1

Echocardiographic parameters of $\mathrm{Npr}^{1^{+/+}}$and $\mathrm{Npr1}^{-/-}$mice before and 7 days after TAC

\begin{tabular}{|c|c|c|c|c|}
\hline & \multicolumn{2}{|c|}{$\mathrm{Npr}^{+/+}(n=19)$} & \multicolumn{2}{|c|}{$N p r 1^{-/-}(n=17)$} \\
\hline & Pre-TAC & Post-TAC & Pre-TAC & Post-TAC \\
\hline $\mathrm{BW}(\mathrm{g})$ & $28.1 \pm 1.1$ & $28.2 \pm 1.1$ & $31.1 \pm 1.2$ & $27.7 \pm 1.4$ \\
\hline LVEDD (mm) & $3.51 \pm 0.12$ & $3.30 \pm 0.10$ & $3.82 \pm 0.16$ & $4.22 \pm 0.15^{\mathrm{A}}$ \\
\hline $\operatorname{LVESD}(\mathrm{mm})$ & $1.75 \pm 0.17$ & $1.61 \pm 0.15$ & $2.17 \pm 0.22$ & $2.76 \pm 0.23^{\mathrm{A}}$ \\
\hline FS (\%) & $52 \pm 3$ & $52 \pm 4$ & $42 \pm 4$ & $36 \pm 4^{B}$ \\
\hline HR (bpm) & $500 \pm 26$ & $544 \pm 29$ & $509 \pm 19$ & $524 \pm 29$ \\
\hline IVSth (mm) & $0.78 \pm 0.03$ & $0.93 \pm 0.04 c$ & $0.96 \pm 0.05^{c}$ & $1.15 \pm 0.04^{\mathrm{A}, \mathrm{D}}$ \\
\hline PWth (mm) & $0.76 \pm 0.04$ & $0.94 \pm 0.03^{C}$ & $0.93 \pm 0.05$ & $1.07 \pm 0.05^{\mathrm{D}}$ \\
\hline $\operatorname{Vcf}(\operatorname{circ} / \mathrm{s})$ & $8.77 \pm 1.5$ & $9.20 \pm 1.5$ & $5.98 \pm 1.2$ & $5.58 \pm 1.2$ \\
\hline $\mathrm{SPG}(\mathrm{mmHg})$ & & $65 \pm 6$ & & $59 \pm 7$ \\
\hline
\end{tabular}

Data is expressed as mean $\pm \mathrm{SE}$. All statistics by unpaired $t$ test with Bonferroni correction. $\mathrm{Npr}^{+/++}(n=8$ male, 11 female $) ; \mathrm{Npr} 1^{-/-}(n=3$ male, 14 female $)$. AP $<0.005$ versus post-TAC Npr1 ${ }^{+/+}$. B $P<0.02$ versus post-TAC Npr1 $1^{+/+}$. C $P<0.05$ versus pre-TAC $N p r 1^{+/+}$. D $P<0.05$ versus pre-TAC Npr $1^{-/-}$. IVSth, interventricular septal wall thickness; PWth, posterior wall thickness; Vcf, velocity of circumferential fiber shortening; SPG, systolic pressure gradient. 
8a). TAC caused an increase in the activation of all four kinases in both $\mathrm{Nprl}^{+/+}$and $\mathrm{Npr1}^{-/-}$animals compared to sham controls of the same genotype (Figure $8 \mathrm{~b}$ ), but there were no differences in the activation of MAPK between $\mathrm{Nprl}^{+/+}$and $\mathrm{Npr}^{-/-}$mice after TAC. Therefore, our data suggest that differences in MAPK activation do not account for the enhanced hypertrophic response seen in $\mathrm{Npr}^{-/-}$mice.

\section{Discussion}

The present study demonstrates that the NPRA system plays a direct role in vivo in moderating cardiac hypertrophy. $\mathrm{Npr}^{-1-}$ mice have increased HW from birth that persists throughout life. Chronic normalization of BP by administration of four antihypertensive agents from weaning to sacrifice as 4-month-old adults does not decrease the degree of cardiac hypertrophy in the $\mathrm{Npr}^{-/-}$mice. In the opposite direction, NPRA-deficient mice have an enhanced response to pressure overload with marked increases in cardiac hypertrophy, LV chamber dilation, and worsening of cardiac function compared with wild-type mice even when the total cardiac load was similar.

Cardiac hypertrophy is characterized by increased production of contractile proteins and reactivation of embryonic genes including induction of fetal contractile gene expression (38). The ANP gene is one of the most robust responders to diverse hypertrophic stimuli, with an increase in both the level of ANP gene expression and the number of cells that produce ANP (39). This induction, considered pathognomonic of cardiac hypertrophy (38), is highly conserved across

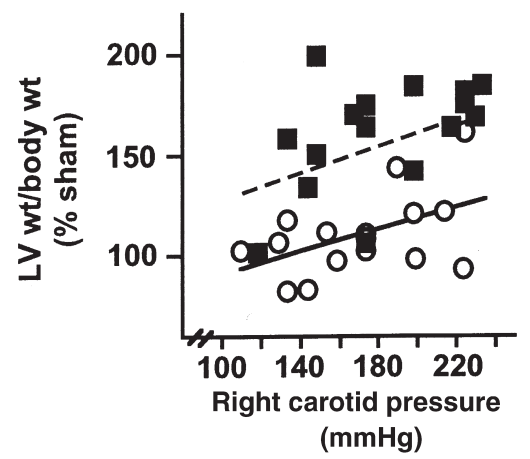

\section{Figure 6}

At any total mechanical load on the heart, $\mathrm{Npr}^{-1-}$ mice have an enhanced hypertrophic response compared with $\mathrm{Npr1}^{+/+}$mice. LV/BW as a function of the total mechanical load on the heart (a factor of both basal BP and the gradient induced by TAC) as measured by the pressure in the right carotid artery proximal to the aortic constriction. Pressures were measured in anesthetized mice 7 days after TAC just before sacrifice. For reference, pressures in $\mathrm{Npr}^{+/+}$sham mice averaged $99 \pm 5$ $\mathrm{mmHg}(n=5)$, indicating that a substantial load was induced by TAC. Data are expressed as percent mean sham LV/body of the same genotype to correct for differences in basal LV/body between $\mathrm{Npr}^{+/+}$and $\mathrm{Npr1}^{-/-}$mice. Open circles indicate $\mathrm{Npr}^{+/+}$TAC mice (filled line represents the best fit for these data), and filled squares indicate $\mathrm{Npr}^{1-/-} \mathrm{TAC}$ mice (dashed line represents the best fit for these data).

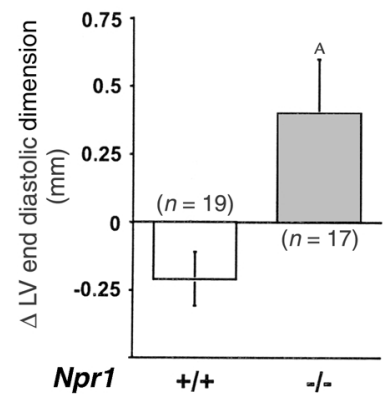

b

\section{Figure 7}

TAC causes LV dilatation and a decline in cardiac function in $\mathrm{Npr}^{-/-}$ mice. (a) The change in LV end diastolic dimension (post-TAC echo measurement; minus pre-TAC echo measurement) in $\mathrm{Npr}^{1^{++}}$and $\mathrm{Npr}^{-1^{--}}$mice that received TAC for 1 week. $\mathrm{Npr}^{+/+}$mice have a normal hypertrophic response to pressure overload with no chamber dilation. In contrast, $\mathrm{Npr}^{-/-}$mice develop dilated cardiac hypertrophy in response to TAC. The SPG is the same for each group (SPG is $65 \pm 6 \mathrm{mmHg}$ in $\mathrm{Npr}^{+/+} \mathrm{TAC}$ mice, and $59 \pm 7 \mathrm{mmHg}$ in $\mathrm{Npr}^{-/-}$ TAC mice). ${ }^{A} P<4.0 \times 10^{-5}$ by Scheffè test for repeated measures. $\mathrm{Npr}^{1^{++}}(n=8$ male, 11 female $) ; \mathrm{Npr}^{-1_{-}}(n=3$ male, 14 female $)$. There were no sex differences. (b) The change in fractional shortening. In $\mathrm{Npr}^{1^{+/}}$mice, TAC for 1 week had no deleterious effect on cardiac function. In $\mathrm{Npr}^{-1-}$ mice, TAC caused a decrease in fractional shortening, indicating worsening cardiac function. ${ }^{\mathrm{B}} P<0.004$ by Scheffe test for repeated measures.

species and leads in turn to a marked elevation in plasma ANP levels $(40,41)$. BNP expression and secretion are also elevated in patients with cardiac hypertrophy and dilated cardiomyopathy $(40,41)$. The presumed function of these circulating natriuretic peptides is to reduce the load on the heart by increasing vasodilation and decreasing body fluid $(4,42,43)$.

Many of the pressor substances that are present at increased levels during heart failure, such as angiotensin II, endothelin- 1 , and $\alpha$-adrenergic agonists, are also potent (positive) inducers of cardiac hypertrophy (43). It is not inconsistent that the natriuretic peptide system, with actions that decrease BP and BV, would also have antihypertrophic (negative) properties. Thus, treatment with ANP in neonatal rat cardiomyocytes stimulated with phenylephrine (PE) decreases $\left[{ }^{3} \mathrm{H}\right]$ leucine incorporation and increases apoptosis. The physiological effects of natriuretic peptides are mediated by the guanylate cyclase activity of NPRA. It is accordingly supportive of the direct effects of the peptides that treatment with agents that increase cGMP levels (such as 8-br-cGMP or zaprinast) also have antihypertrophic and apoptotic effects $(13,18-20)$. Finally, in vivo evidence from genetically modified animal models also supports an antihypertrophic role for the NPRA system. Transgenic overexpression of ANP causes a decrease in HW and prevents RV hypertrophy induced by pulmonary hypertension (44). Both NPRAand ANP-deficient mice have increased HW/BW (21, 45 ), although these studies do not discriminate 

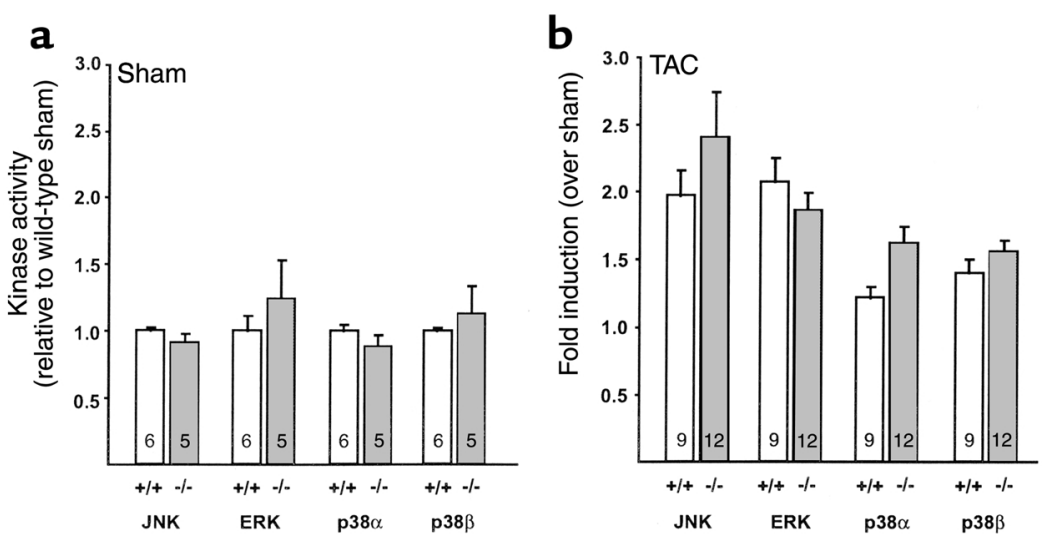

\section{Figure 8}

MAPK activation in $\mathrm{Npr}^{1^{+/+}}$and $\mathrm{Npr}^{-/-}$mice. (a) Basal MAPK activity in sham-operated $\mathrm{Npr}^{1^{-/-}}$mice expressed as relative activity of $\mathrm{Npr} 1^{+/+}$ mice. Differences between $\mathrm{Npr}^{+/++}$and $\mathrm{Npr}^{-/-}$mice were not significant. Numbers in the bars indicate the number of animals. A subset of animals were used in this analysis. (b) Fold increase of MAPK activity by TAC. Data are expressed as fold induction ( \pm SE) over sham controls of the same genotype. Numbers inside bars represent the number of animals. All four MAPKs were significantly activated versus sham of the same genotype $\left(P<0.05\right.$ by ANOVA with Bonferroni correction). There was no significant difference in activation of any MAPK between $N p r 1^{+/+}$and $\mathrm{Npr}^{-1-}$ mice after TAC.

between cardiac hypertrophy due to the loss of a primary antihypertrophic effect and hypertrophy secondary to the increase in BP. Mice lacking BNP do not display increased BP or cardiac hypertrophy, although they do develop cardiac fibrosis, suggesting an antifibrotic role for BNP (46).

The signaling pathways that govern cardiac hypertrophy are just beginning to be understood. The best characterized of these hypertrophic pathways is the MAPK signaling cascade including JNK, ERK $1 / 2$, and p38 (both the $\alpha$ and $\beta$ isoforms). These MAPKs are the central effectors of diverse hypertrophic stimuli such as angiotensin II, endothelin- $1, \alpha$-adrenergic agonists, and pressure overload $(10,47-50)$, and all four are induced by TAC in both $\mathrm{NprI}^{+/+}$and $\mathrm{Npr1}^{-/-}$mice (Figure 8). It is interesting that both the basal activities of MAPK and their induction by TAC were not different in the $\mathrm{NprI}^{+/+}$and $\mathrm{Npr1}^{-/-}$mice despite a much enhanced hypertrophic response to TAC in the NPRAnull mice. Although we do not have direct evidence, it suggests that the growth-regulating properties of the NPRA signaling pathway operate through mechanisms downstream and/or distinct from these MAPK cascades. Thus, the relative activation of MAPKs does not appear to be a controlling factor in the hypertrophic response in $\mathrm{Npr}^{-/-}$mice caused by pressure overload. Further investigation is needed to determine what other effectors are playing a role in the enhanced hypertrophic response seen in these mice.

In our experiments, chronic BP normalization by several drugs with very different mechanisms of action and different hemodynamic properties failed to decrease $\mathrm{HW} / \mathrm{BW}$ in $\mathrm{Npr1}^{-/-}$mice. These include an ACE inhibitor (enalapril), an angiotensin II receptor blocker (losartan), and a diuretic (furosemide) that have all been shown to be very effective in preventing or reversing LVH in animals including mice $(37,51-58)$. Thus, in
$\mathrm{Npr}^{-/-}$mice BP independent stimuli contribute to the development of LVH. The natural history of cardiac hypertrophy in NPRA-deficient mice also emphasizes the BP-independent nature of their increased cardiac mass. During fetal development, the BP is very low because BP is controlled by the maternal/fetal circulatory system. It is not until after birth the $\mathrm{Npr1}^{-/-}$mice would be exposed to an elevated BP (59). The fact that the $\mathrm{Npr}^{-/-}$mice have increased HW at birth is further evidence that the cardiac hypertrophy in these mice is not simply BP dependent.

It is not clear at present what growth-promoting stimuli are causing the increased cardiac mass in $\mathrm{Npr}^{-/-}$mice under basal conditions. Judged by the normal hematocrits, water intake, BW, and urine output, it is unlikely that volume overload is the major factor. One surprising conclusion from the results of chronic antihypertensive treatment of $\mathrm{Npr}^{-1-}$ mice is that absence of NPRA not only uncouples the tight correlation between cardiac growth and BP, but also that cardiac hypertrophy due to absence of NPRA can develop and/or persist even in the absence of elevated BP and when the local effects of hypertrophic stimuli like angiotensin II or $\beta$-adrenergic signaling are blocked $(33,60-62)$. Nevertheless, under the severe stress of mechanical overload $\mathrm{Npr}^{-/-}$mice have an exaggerated response at any total load, suggesting that these mice have a differential response to growth stimuli that are activated by pressure overload. Pathways other than the MAPK signaling cascade are likely to be involved in this enhanced response. Further investigation of the pathways through which NPRA exerts it antihypertrophic effects are needed to increase our basic understanding of and ability to control cardiac hypertrophy, which is sometimes beneficial but more often a harmful adaptation. 
Our results provide direct evidence that the NPRA system moderates the cardiac response to hypertrophic stimuli, even when BPs are essentially normal. Thus, loss-of-function mutations in the NPRA gene (63) should be considered as potential candidates for causing cardiac hypertrophy in humans.

\section{Acknowledgments}

The authors thank Kristine Hesser and David Carraway for technical assistance, and Michael Goy for helpful comments. This work was supported by NIH grants (HL-62845 to N. Maeda; HL-46345 to H.A. Rockman; and GM-20069 to O. Smithies).

1. Espiner, E.A. 1994. Physiology of natriuretic peptides. J. Intern. Med. 235:527-541.

2. Maack, T. 1996. Role of atrial natriuretic factor in volume control. Kidney Int. 49:1732-1737.

3. Kishimoto, I., and Garbers, D.L. 1997. Physiological regulation of blood pressure and kidney function by guanylyl cyclase isoforms. Curr. Opin. Nephrol. Hypertens. 6:58-63.

4. Levin, E.R., Gardner, D.G., and Samson, W.K. 1998. Natriuretic peptides. N. Engl. J. Med. 339:321-328.

5. Clerico, A., Iervasi, G., and Mariani, G. 1999. Pathophysiologic relevance of measuring the plasma levels of cardiac natriuretic peptide hormones in humans. Horm. Metab. Res. 31:487-498.

6. Sagnella, G.A. 1998. Measurement and significance of circulating natriuretic peptides in cardiovascular disease. Clin. Sci. (Colch.) 95:519-529.

7. Rockman, H.A., Knowlton, K.U., Ross, J.R.J., and Chien, K.R. 1993. In vivo murine cardiac hypertrophy. Circulation. 87:VII-14-VII-21.

8. Schrier, R.W., and Abraham, W.T. 1999. Hormones and hemodynamics in heart failure. N. Engl. J. Med. 341:577-585.

9. Knowlton, K.U., et al. 1995. Divergent pathways mediate the induction of ANF transgenes in neonatal and hypertrophic ventricular myocardium. J. Clin. Invest. 96:1311-1318.

10. Glennon, P.E., et al. 1996. Depletion of mitogen-activated protein kinase using an antisense oligodeoxynucleotide approach downregulates the phenylephrine-induced hypertrophic response in rat cardiac myocytes. Circ. Res. 78:954-961.

11. Gillespie-Brown, J., Fuller, S.J., Bogoyevitch, M.A., Cowley, S., and Sugden, P.H. 1995. The mitogen-activated protein kinase kinase MEK1 stimulates a pattern of gene expression typical of the hypertrophic phenotype in rat ventricular cardiomyocytes. J. Biol. Chem. 270:28092-28096.

12. Sadoshima, J., Jahn, L., Takahashi, T., Kulik, T.J., and Izumo, S. 1992. Molecular characterization of the stretch-induced adaptation of cultured cardiac cells. An in vitro model of load-induced cardiac hypertrophy. J. Biol. Chem. 267:10551-10560.

13. Calderone, A., Thaik, C.M., Takahashi, N., Chang, D.L.F., and Colucci, W.S. 1998. Nitric oxide, atrial natriuretic peptide, and cyclic GMP inhibit the growth-promoting effects of norepinephrine in cardiac myocytes and fibroblasts. J. Clin. Invest. 101:812-818.

14. Itoh, H., Pratt, R.E., Ohno, M., and Dzau, V.J. 1992. Atrial natriuretic polypeptide as a novel antigrowth factor of endothelial cells. Hypertension. 19:758-761.

15. Itoh, H., Pratt, R.E., and Dzau, V.J. 1990. Atrial natriuretic polypeptide inhibits hypertrophy of vascular smooth muscle cells. J. Clin. Invest. 86:1690-1697.

16. Hutchinson, H.G., Trindade, P.T., Cunanan, D.B., Wu, C.F., and Pratt, R.E. 1997. Mechanisms of natriuretic-peptide-induced growth inhibition of vascular smooth muscle cells. Cardiovasc. Res. 35:158-167.

17. Kumar, R., Cartledge, W.A., Lincoln, T.M., and Pandey, K.N. 1997. Expression of guanylyl cyclase-A/atrial natriuretic peptide receptor blocks the activation of protein kinase $\mathrm{C}$ in vascular smooth muscle cells. Role of cGMP and cGMP-dependent protein kinase. Hypertension. 29:414-421.

18. Horio, T., et al. 2000. Inhibitory regulation of hypertrophy by endogenous atrial natriuretic peptide in cultured cardiac myocytes. Hyperten sion 35:19-24.

19. Silberbach, M., et al. 1999. Extracellular signal-regulated protein kinase activation is required for the anti-hypertrophic effect of atrial natriuretic factor in neonatal rat ventricular myocytes. J. Biol. Chem. 274:24858-24864.

20. Wu, C.F., Bishopric, N.H., and Pratt, R.E. 1997. Atrial natriuretic peptide induces apoptosis in neonatal rat cardiac myocytes. J. Biol. Chem. 272:14860-14866.

21. Oliver, P.M., et al. 1997. Hypertension, cardiac hypertrophy, and sudden death in mice lacking natriuretic peptide receptor A. Proc. Natl. Acad. Sci. USA. 94:14730-14735.

22. Shesely, E.G., et al. 1996. Elevated blood pressures in mice lacking endothelial nitric oxide synthase. Proc. Natl. Acad. Sci. USA. 93:13176-13181.

23. Krege, J.H., Hodgin, J.B., Hagaman, J.R., and Smithies, O. 1995. A noninvasive computerized tail-cuff system for measuring blood pressure in mice. Hypertension. 25:1111-1115.

24. Rockman, H.A., et al. 1991. Segregation of atrial-specific and inducible expression of an atrial natriuretic factor transgene in an in vivo murine model of cardiac hypertrophy [erratum 1991, 88:9907]. Proc. Natl. Acad. Sci. USA. 88:8277-8281.

25. Esposito, G., et al. 2000. Cellular and functional defects in a mouse model of heart failure. Am. J. Physiol. Heart Circ. Physiol. 279:H3101-H3112.

26. Esposito, G., Naga Prasad, S.V., Mao, L., Koch, W.J., and Rockman, H.A. 2001. Cardiac overexpression of a G(q) inhibitor blocks induction of extracellular signal-regulated kinase and C-JunNH(2)-terminal kinase activity in in vivo pressure overload. Circulation. 103:1453-1458.

27. Lopez, M.J., et al. 1995. Salt-resistant hypertension in mice lacking the guanylyl cyclase-A receptor for atrial natriuretic peptide. Nature. 378:65-68.

28. Dubois, S.K., Kishimoto, I., Lillis, T.O., and Garbers, D.L. 2000. A genetic model defines the importance of the atrial natriuretic peptide receptor (guanylyl cyclase-A) in the regulation of kidney function. Proc. Natl. Acad. Sci. USA. 97:4369-4373.

29. Kannel, W.B. 1995. Clinical misconceptions dispelled by epidemiological research. Circulation. 92:3350-3360.

30. Mosterd, A., et al. 1999. Trends in the prevalence of hypertension, antihypertensive therapy, and left ventricular hypertrophy from 1950 to 1989. N. Engl. J. Med. 340:1221-1227.

31. Greenberg, B., et al. 1995. Effects of long-term enalapril therapy on cardiac structure and function in patients with left ventricular dysfunction. Results of the SOLVD echocardiography substudy. Circulation. 91:2573-2581.

32. Gottdiener, J.S., et al. 1997. Effect of single-drug therapy on reduction of left ventricular mass in mild to moderate hypertension: comparison of six antihypertensive agents. The Department of Veterans Affairs Cooperative Study Group on Antihypertensive Agents. Circulation. 95:2007-2014.

33. Friddle, C.J., Koga, T., Rubin, E.M., and Bristow, J. 2000. Expression profiling reveals distinct sets of genes altered during induction and regression of cardiac hypertrophy. Proc. Natl. Acad. Sci. USA. 97:6745-6750.

34. Gupta, M., and Gupta, M.P. 1997. Cardiac hypertrophy: old concepts, new perspectives. Mol. Cell. Biochem. 176:273-279.

35. Cutilletta, A.F. 1984. Myosin heavy chain mRNA during the development and regression of myocardial hypertrophy. Eur. Heart J. 5(Suppl.):193-197.

36. Bishop, J.E., Kiernan, L.A., Montgomery, H.E., Gohlke, P., and McEwan, J.R. 2000. Raised blood pressure, not renin-angiotensin systems, causes cardiac fibrosis in TGR m(Ren2)27 rats. Cardiovasc. Res. 47:57-67.

37. Kai, T., Sugimura, K., Shimada, S., Kurooka, A., and Ishikawa, K. 1999. Renin-angiotensin system stimulates cardiac and renal disorders in Tsukuba hypertensive mice. Clin. Exp. Pharmacol. Physiol. 26:206-211.

38. Hunter, J.J., and Chien, K.R. 1999. Signaling pathways for cardiac hypertrophy and failure. N. Engl. J. Med. 341:1276-1283.

39. Lattion, A.L., Michel, J.B., Arnauld, E., Corvol, P., and Soubrier, F. 1986. Myocardial recruitment during ANF mRNA increase with volume overload in the rat. Am. J. Physiol. 251:H890-H896.

40. Hasegawa, K., et al. 1993. Ventricular expression of brain natriuretic peptide in hypertrophic cardiomyopathy. Circulation. 88:372-380.

41. Hasegawa, K., et al. 1993. Ventricular expression of atrial and brain natriuretic peptides in dilated cardiomyopathy. An immunohistocytochemical study of the endomyocardial biopsy specimens using specific monoclonal antibodies. Am. J. Pathol. 142:107-116.

42. Saito, Y., et al. 1989. Augmented expression of atrial natriuretic polypeptide gene in ventricle of human failing heart. J. Clin. Invest. 83:298-305.

43. Jackson, G., Gibbs, C.R., Davies, M.K., and Lip, G.Y. 2000. ABC of heart failure. Pathophysiology. BMJ. 320:167-170.

44. Klinger, J.R., et al. 1993. Cardiopulmonary responses to chronic hypoxia in transgenic mice that overexpress ANP. J. Appl. Physiol. 75:198-205.

45. John, S.W., et al. 1995. Genetic decreases in atrial natriuretic peptide and salt-sensitive hypertension [erratum 1995, 267:1753]. Science. 267:679-681.

46. Tamura, N., et al. 2000. Cardiac fibrosis in mice lacking brain natriuretic peptide. Proc. Natl. Acad. Sci. USA. 97:4239-4244.

47. Thorburn, A., et al. 1993. HRas-dependent pathways can activate morphological and genetic markers of cardiac muscle cell hypertrophy [erratum 1993, 268:16082]. J. Biol. Chem. 268:2244-2249.

48. Wang, Y., et al. 1998. Cardiac muscle cell hypertrophy and apoptosis induced by distinct members of the p38 mitogen-activated protein kinase family. J. Biol. Chem. 273:2161-2168.

49. Wang, Y., et al. 1998. Cardiac hypertrophy induced by mitogen-activated protein kinase kinase 7 , a specific activator for c-Jun NH2-terminal kinase in ventricular muscle cells. J. Biol. Chem. 273:5423-5426.

50. Choukroun, G., et al. 1999. Regulation of cardiac hypertrophy in vivo by the stress-activated protein kinases/c-Jun $\mathrm{NH}(2)$-terminal kinases. J. Clin. 
Invest. 104:391-398.

51. Pfeffer, J.M., Pfeffer, M.A., Mirsky, I., and Braunwald, E. 1982. Regression of left ventricular hypertrophy and prevention of left ventricular dysfunction by captopril in the spontaneously hypertensive rat. Proc. Natl. Acad. Sci. USA. 79:3310-3314.

52. Brilla, C.G., Janicki, J.S., and Weber, K.T. 1991. Cardioreparative effects of lisinopril in rats with genetic hypertension and left ventricular hypertrophy. Circulation. 83:1771-1779.

53. Rockman, H.A., Wachhorst, S.P., Mao, L., and Ross, J., Jr. 1994. ANG II receptor blockade prevents ventricular hypertrophy and ANF gene expression with pressure overload in mice. Am. J. Physiol. 266:H2468-H2475.

54. Nunez, E., Hosoya, K., Susic, D., and Frohlich, E.D. 1997. Enalapril and losartan reduced cardiac mass and improved coronary hemodynamics in SHR. Hypertension. 29:519-524.

55. Bocker, W., Hupf, H., Grimm, D., Kurzidim, K., and Schunkert, H. 2000 Effects of indapamide in rats with pressure overload left ventricular hypertrophy. J. Cardiovasc. Pharmacol. 36:481-486.

56. Kim, S., et al. 1996. Molecular effects of M17055, furosemide and thiazide on cardiac hypertrophy of spontaneously hypertensive rats. $J$. Pharmacol. Exp. Ther. 279:983-990.

57. Pinto, Y.M., Paul, M., and Ganten, D. 1998. Lessons from rat models of hyper- tension: from Goldblatt to genetic engineering. Cardiovasc. Res. 39:77-88.

58. Tea, B.S., Dam, T.V., Moreau, P., Hamet, P., and deBlois, D. 1999. Apoptosis during regression of cardiac hypertrophy in spontaneously hypertensive rats. Temporal regulation and spatial heterogeneity. Hypertension. 34:229-235.

59. Thornburg, K.L., and Morton, M.J. 1994. Development of the cardiovascular system. In Textbook of fetal physiology. Volume 1. G.D. Thorburn and R. Harding, editors. Oxford University Press. New York, New York, USA. 95-130.

60. Susic, D., Nunez, E., Frohlich, E.D., and Prakash, O. 1996. Angiotensin II increases left ventricular mass without affecting myosin isoform mRNAs. Hypertension. 28:265-268.

61. Ieki, K., et al. 1989. Effect of long-term treatment with beta-blocker on cardiac hypertrophy in SHR. J. Mol. Cell. Cardiol. 21(Suppl.):113-119.

62. Sen, S., Tarazi, R.C., and Bumpus, F.M. 1977. Cardiac hypertrophy and antihypertensive therapy. Cardiovasc. Res. 11:427-433.

63. Nakayama, T., et al. 2000. Functional deletion mutation of the 5 '-flanking region of type A human natriuretic peptide receptor gene and its association with essential hypertension and left ventricular hypertrophy in the Japanese. Circ. Res. 86:841-845. 